\title{
PEHO syndrome: the endpoint of different genetic epilepsies
}

\author{
Manali Chitre, ${ }_{1}^{1}$ Michael S Nahorski, ${ }^{2}$ Kaitlin Stouffer, ${ }^{2}$ Bryony Dunning-Davies, ${ }^{1}$ \\ Hamish Houston, ${ }^{1}$ Emma L Wakeling, ${ }^{3}$ Angela F Brady, ${ }^{3}$ Sameer M Zuberi, ${ }^{4}$ \\ Mohnish Suri, ${ }^{5}$ Alasdair P J Parker, ${ }_{1}^{1}$ C Geoffrey Woods ${ }^{2}$
}

'Department of Paediatric Neurology, Cambridge University Hospitals NHS Foundation Trust, Cambridge, UK

${ }^{2}$ Cambridge Institute for Medical Research, University of Cambridge, Cambridge, UK ${ }^{3}$ North West Thames Regional Genetics Service, London North West Healthcare NHS Trust, Harrow, UK

${ }^{4}$ Paediatric Neurosciences Research Group, Royal Hospital for Children \& University of Glasgow, Glasgow, UK ${ }^{5}$ Nottingham Clinical Genetics Service, Nottingham University Hospitals NHS Trust, Nottingham, UK

\section{Correspondence to}

Dr Manali Chitre, Department of Paediatric Neurology, Child Development Centre Addenbrookes Hospital, Cambridge CB2 OQQ, UK; manali.chitre@addenbrookes. nhs.uk

Received 20 February 2018 Revised 10 July 2018 Accepted 17 August 2018 Published Online First 4 October 2018

\section{Linked}

- http://dx.doi.org/10.1136/ jmedgenet-2018-105650

\section{Check for updates}

(C) Author(s) (or their employer(s)) 2018. No commercial re-use. See rights and permissions. Published by BMJ.

To cite: Chitre M,

Nahorski MS, Stouffer K, et al. $J$ Med Genet

2018:55:803-813

\section{ABSTRACT \\ Background Progressive encephalopathy,} hypsarrhythmia and optic atrophy (PEHO) has been described as a clinically distinct syndrome. It has been postulated that it is an autosomal recessive condition. However, the aetiology is poorly understood, and the genetic basis of the condition has not been fully elucidated. Our objective was to discover if PEHO syndrome is a single gene disorder.

Method Children with PEHO and PEHO-like syndrome were recruited. Clinical, neurological and dysmorphic features were recorded; EEG reports and MRI scans were reviewed. Where possible, exome sequencing was carried out first to seek mutations in known early infantile developmental and epileptic encephalopathy (DEE) genes and then to use an agnostic approach to seek novel candidate genes. We sought intra-interfamilial phenotypic correlations and genotype-phenotype correlations when pathological mutations were identified.

Results Twenty-three children were recruited from a diverse ethnic background, 19 of which were suitable for inclusion. They were similar in many of the core and the supporting features of PEHO, but there was significant variation in MRI and ophthalmological findings, even between siblings with the same mutation. A pathogenic genetic variant was identified in 15 of the 19 children. One further girl's DNA failed analysis, but her two affected sisters shared confirmed variants. Pathogenic variants were identified in seven different genes. Conclusions We found significant clinical and genetic heterogeneity. Given the intrafamily variation demonstrated, we question whether the diagnostic criteria for MRI and ophthalmic findings should be altered. We also question whether PEHO and PEHOlike syndrome represent differing points on a clinical spectrum of the DEE. We conclude that PEHO and PEHO-like syndrome are clinically and genetically diverse entities - and are phenotypic endpoints of many severe genetic encephalopathies.

\section{INTRODUCTION}

Progressive encephalopathy, hypsarrhythmia and optic atrophy (PEHO) has been described as a clinically distinct syndrome of likely autosomal recessive genetic aetiology with a devastating prognosis for the affected child and their family.

This condition was first reported by Salonen et al in a group of Finnish patients. ${ }^{1}$ They described a progressive infantile encephalopathy with severe early hypotonia, developmental regression and convulsions. The seizures were usually myoclonias or infantile spasms with hypsarrhythmia that were unresponsive to antiepileptic medication. The children had absence or loss of visual fixation, and optic atrophy was detectable by ophthalmoscopy before 2 years. At birth, they displayed oedema in the face and limbs, acquired (secondary) microcephaly and dysmorphismsincluding pear-shaped face, epicanthic folds, short nose, persistently open mouth and tapering fingers.

An early neuropathological study of eight cases demonstrated atrophy of the optic nerve and cerebellar cortex. ${ }^{2}$ The Purkinje cells were small, deformed and misaligned with evidence of disrupted cytoskeletal architecture.

Subsequently, Somer (1993) proposed criteria she considered necessary for diagnosing PEHO syndrome. ${ }^{3}$ She defined particular neuro-ophthalmological and radiological criteria: loss of visual fixation, atrophy of the optic discs by 2 years, normal electroretinogram and lack of visual evoked potentials (VEPs); progressive brain atrophy on neuroimaging predominately affecting the cerebellum and brainstem, with milder atrophy in the cerebrum. ${ }^{45}$ EEG findings are not mentioned in Somer's diagnostic criteria, but in a serial EEG study of children with PEHO, all developed typical treatment-resistant hypsarrhythmia between 3 and 11 months of age, hence the inclusion in the syndrome's acronymic name. ${ }^{5}$

Somer also described a PEHO-like syndrome with indistinguishable facial features, but without either optic nerve and/or infratentorial atrophy. ${ }^{3}$ They felt that the children with only mild cerebral atrophy on MRI had subtle clinical differences to the PEHO group and hence should not be considered to have the true PEHO syndrome. Chitty et al later reported three severely affected children who met all the other criteria for PEHO syndrome, but had generalised cerebral atrophy. ${ }^{6}$ They met the same developmental endpoint as the previously described PEHO cases, raising the question as to whether the diagnostic criteria for PEHO should include the more generalised findings of brain atrophy.

Apart from the Finnish patients, cases of PEHO and PEHO-like syndrome have been reported in other countries and ethnic groups. Some have questioned Somer's distinction between classical PEHO and PEHO-like syndromes. ${ }^{67}$ The exclusion 
of children without infratentorial atrophy on MRI is debated. These groups suggested that these phenotypes may not represent unique pathological processes, but rather a spectrum of presentations caused by a severe disease. Field et al suggested that the Finnish cohort may represent 'a homogeneous subgroup of a single disorder'. ${ }^{7}$ Salpietro et $a l^{8}$ argued that finding Italian siblings with an identical phenotype to Somer's supported the existence of more than one distinct disorder. ${ }^{8}$

In addition to cerebellar and brainstem atrophy, several other imaging findings have been reported in patients with PEHO and PEHO-like syndrome including cerebral atrophy, ${ }^{3} 7$ 9-11 hypoplastic corpus callosum ${ }^{611-15}$ and abnormal signal intensity of the cerebral white matter. ${ }^{4611} 16$ Serial MRI studies have demonstrated the progressive nature of the imaging findings. ${ }^{17} 18$ The absence of cerebellar atrophy in some children may represent early timing of investigations/mortality. ${ }^{7}$

A biochemical aetiology has not been elucidated, although decreased levels of insulin-like growth factor and increased nitrate/nitrite levels have been described in the cerebrospinal fluid of some Finnish cases. ${ }^{19} 20$

An autosomal recessive pattern of inheritance has been indicated by families where different sex siblings are affected and by patients with consanguineous parents. However, no single gene has been identified as causative. ${ }^{116}$ It is not surprising that the Finnish cohort shows more clinical and radiological homogeneity than case reports involving patients with various ethnicities. While most cases and families are recessive, an autosomal dominant form of PEHO syndrome has been described. Variable expressivity seen in a dominant KIF1A variant affecting the motor domain of the protein has also been suggested to cause the full or partial phenotype of PEHO syndrome in a subset of patients. ${ }^{21}$ Gawlinski et al reported the PEHO phenotype in disease-causing mutations in known variants associated with neurodevelopmental disorders, for example, CDKL5. In a child with both GNAO1 and HESX1 gene variants, they hypothesised that a complex PEHO phenotype with optic atrophy could result from aggregated effect of genetic variants at two loci. ${ }^{22}$

Identifying the aetiology is essential for genetic counselling and understanding the role of the abnormalities in normal brain function-hopefully leading to improved or new therapies. We present a case series of 19 children with a diagnosis of PEHO or PEHO-like syndrome. We suggest that the PEHO or PEHO-like phenotype may be seen in several infantile developmental and epileptic encephalopathies with diverse genetic aetiologies.

\section{METHODS}

\section{Patient selection}

Children with PEHO or PEHO-like syndrome were recruited through our own practices, national collaborators and requests for cases via the British Paediatric Neurology Association, European Paediatric Neurology Society and UK Clinical Genetics Society. The inclusion criteria were that they met the diagnostic criteria for either PEHO or PEHO-like syndrome ${ }^{36}$ (for a diagnosis of PEHO, a child must have all of the essential diagnostic criteria; table 1). Research ethics approval was gained for the clinical and molecular aspects of the project, and families contacted directly for consent to use photographs.

Where children died before the age of 2 years, we assigned the diagnosis in the absence of optic atrophy as this feature is progressive and not expected to be present in infancy. To make a diagnosis of PEHO-like syndrome, a child may not have all of the features; in particular, they may lack either diagnostic MRI changes or optic atrophy. Radiology was reviewed with an
Table 1 Clinical criteria for the diagnosis of PEHO syndrome as described by Somer ${ }^{3}$

\begin{tabular}{|c|c|c|}
\hline Necessary criteria & Supportive criteria & $\begin{array}{l}\text { Features that argue against } \\
\text { the PEHO syndrome }\end{array}$ \\
\hline $\begin{array}{l}\text { Infantile, usually neonatal } \\
\text { hypotonia }\end{array}$ & $\begin{array}{l}\text { Subtle dysmorphic } \\
\text { features with narrow } \\
\text { forehead, epicanthic } \\
\text { folds, short nose, open } \\
\text { mouth, receding chin, } \\
\text { tapering fingers }\end{array}$ & Microcephaly at birth \\
\hline $\begin{array}{l}\text { Convulsive disorder } \\
\text { manifesting with } \\
\text { myoclonic seizures and } \\
\text { infantile spasms }\end{array}$ & $\begin{array}{l}\text { Oedema of the face } \\
\text { and limbs, especially } \\
\text { in early childhood }\end{array}$ & $\begin{array}{l}\text { Abnormal gyral formation in } \\
\text { neuroradiological studies }\end{array}$ \\
\hline $\begin{array}{l}\text { Profound psychomotor } \\
\text { retardation with severe } \\
\text { hypotonia; absence of } \\
\text { motor milestones and } \\
\text { speech }\end{array}$ & $\begin{array}{l}\text { Brisk tendon reflexes } \\
\text { in early childhood }\end{array}$ & $\begin{array}{l}\text { Predominating spasticity in } \\
\text { infancy }\end{array}$ \\
\hline $\begin{array}{l}\text { Absence or early loss of } \\
\text { visual fixation with atrophy } \\
\text { of optic discs by } 2 \text { years; } \\
\text { normal electroretinogram, } \\
\text { extinguished visual evoked } \\
\text { potentials }\end{array}$ & $\begin{array}{l}\text { Abnormal brainstem } \\
\text { auditory evoked } \\
\text { potentials }\end{array}$ & $\begin{array}{l}\text { Reappearance of visual contact } \\
\text { after cessation of infantile } \\
\text { spasms }\end{array}$ \\
\hline \multirow{3}{*}{$\begin{array}{l}\text { Progressive brain atrophy } \\
\text { in neuroimaging studies, } \\
\text { particularly in the } \\
\text { cerebellum and brainstem; } \\
\text { milder supratentorial } \\
\text { atrophy }\end{array}$} & $\begin{array}{l}\text { Absent cortical } \\
\text { responses of } \\
\text { somatosensory } \\
\text { evoked potentials }\end{array}$ & $\begin{array}{l}\text { Hepato/splenomegaly or storage } \\
\text { disorder in histological studies }\end{array}$ \\
\hline & $\begin{array}{l}\text { Slow nerve } \\
\text { conduction velocities } \\
\text { in late childhood }\end{array}$ & \\
\hline & $\begin{array}{l}\text { Dysmyelination on } \\
\text { MRI }\end{array}$ & \\
\hline
\end{tabular}

PEHO, progressive encephalopathy, hypsarrhythmia and optic atrophy.

experienced paediatric neuroradiologist. A child was also given a provisional diagnosis of PEHO-like syndrome if they had all the features of PEHO, but displayed some features listed in table 1 that argue against a diagnosis of PEHO. However, children were excluded if they did not have all the features of PEHO and had any of the features that argue against the diagnosis.

Clinical, neurological and dysmorphic features were recorded, and EEG reports and MRIs were reviewed. Where it was not possible to review the child (as they were deceased), case notes were reviewed, and clinical findings and investigations were recorded.

\section{Molecular methods}

Children had DNA extracted by standard methods, and a microarray and exome were performed. The results of each exome were analysed first for known genetic causes of early infantile epileptic encephalopathies (EIEEs) (using a virtual panel approach), and if no mutations were found, then we sought pathogenic mutations using presumed de novo autosomal dominant, autosomal recessive and X-linked Mendelian inheritance using an agnostic approach to include all genes as initial candidates and then standard bioinformatics approaches to select likely candidate gene mutations. ${ }^{23-25}$ Where there were multiple family members or consanguinity, this process was eased by seeking either concordance of mutations in affected family members or homozygous mutations within homozygous chromosomal regions. In some families, it was impossible for 
us to determine likely pathogenic variant(s) in a single gene. All potential pathogenic mutations were confirmed by Sanger sequencing of affected children and, wherever possible, their parents. ${ }^{23}$ We sought intra-interfamilial phenotypic correlations and genotype-phenotype correlations when pathological mutations were identified.

\section{RESULTS}

\section{Study recruitment}

The 23 children recruited into the study were from 14 families. The majority were from the UK but from differing racial backgrounds, including British, Arabic, Sudanese and Pakistani children (three Pakistani families). One 'PEHO-like' case, subsequently found to have biallelic pathogenic variants in RARS2, was included in the study, but excluded from the analysis. ${ }^{27}$ One child was excluded as there was insufficient information to allow classification. In a PEHO sib pair, we found a pathogenic homozygous variant $\mathrm{p}$.(Asp106Asn) in PRUNE, but they were subsequently reported ${ }^{28-30}$ and so were excluded from the study. Nineteen children from 11 families were reviewed, 7 had PEHO and 12 had PEHO-like syndrome.

Of the 12 children with PEHO-like syndrome, two could not be classified as PEHO because of missing data. In two cases, we removed the diagnosis of PEHO because of a history of hypertonia in early life, though later their tone was noted to be low normal. In three cases, despite fulfilling all the criteria of PEHO, there were also features that were deemed not in keeping with the diagnosis, including microcephaly present at birth and abnormal neuronal migration on MRI. Two children diagnosed with PEHO lacked evidence of optic atrophy-both died under 2 years-before optic atrophy would have developed. We were unable to sequence DNA from one child.

Five of the 19 children studied came from consanguineous families. Three families (families A, B and C) had multiple affected children. One of these (family $\mathrm{C}$ ) was consanguineous. PEHO and PEHO-like syndrome occurred within a family; family A had five affected children, three with PEHO-like syndrome and two with PEHO.

\section{Essential features for the diagnosis of PEHO}

All of the children (PEHO and PEHO-like syndrome) had delayed psychomotor development. All had seizures (figure 1A) that included infantile spasms and had highly abnormal EEGs. Seventeen of the children had severe hypotonia, whereas two had initial hypertonia followed by low tone.

All children with PEHO were unable to fixate visually; two did not have optic atrophy (essential criteria), but died by the age of 2 years, potentially precluding its development. All but 1 of the 12 children with PEHO-like syndrome were unable to fixate. Four did not have optic disc atrophy. One died before they were 2 years old, one was not examined by an ophthalmologist after the age of 6 months, one had pale optic discs and one was noted to have absent VEPs at 4 months, but there was no information on their optic discs.

\section{MRI findings}

All of the children with PEHO had cerebellar atrophy, but other features varied. Two had cerebellar atrophy alone, two had other infratentorial atrophy and three had global atrophy with more predominant changes in the cerebellum (figure $1 \mathrm{~B}$ and figure 2).

Seven of the children with PEHO-like syndrome had no cerebellar atrophy; in four, it was the lack of cerebellar atrophy that excluded them from a diagnosis of PEHO. Of the seven with no cerebellar atrophy, two had no MRI scans, two had normal MRIs which were done at an early age (less than 1 year) and three had abnormal MRIs with changes supportive of a PEHO diagnosis, but no cerebellar changes (one of these was done at age 7 months and the ages at which the other two were done are unknown). The five who displayed cerebellar atrophy also had evidence of abnormal migration.

Dysmyelination was reported in three children with PEHOlike syndrome and one child with PEHO.

\section{EEG findings}

Four of the 7 children with PEHO and 7 out of the 12 with PEHO-like features had an EEG showing classical hypsarrhythmia. Three of the children's EEGs were not available for review; one was abnormal, but not classical for hypsarrhythmia. The remaining four were highly abnormal and may have been consistent with modified hypsarrhythmia.

\section{Features supportive of the diagnosis}

All children had strikingly similar dysmorphic features supportive of the diagnosis of PEHO (figure 2). One of the children did not have the characteristic oedema of the face and limbs, and in one sibling, this feature was not recorded in their notes.

The other findings listed in the supportive diagnostic criteria were not recorded for many of the children studied. ${ }^{3}$ These include brisk tendon reflexes in early childhood, abnormal brainstem auditory evoked potentials, absent cortical responses of somatosensory evoked potentials and slow nerve conduction velocities in late childhood. VEPs had been measured in only one of the children studied.

A further feature which is not listed in the supportive criteria, but which is of interest, is a striking somnolence which was seen in these children. This feature was remarked on in the notes of 18 out of 19 children studied.

\section{Description of specific families within the cohort}

Phenotypes and genotypes are detailed in table 2.

Our cohort included three families with multiple children affected by PEHO and PEHO-like syndrome.

Family A was made up of 11 siblings and 2 half-siblings, of which 5 children were affected (figure 3A). The parents had mild learning difficulties. Of the five affected children, the eldest and youngest (children 1 and 5) met the criteria for PEHO, whereas the other three (children 2, 3 and 4) were PEHO-like syndrome. All five children displayed profound hypotonia. All had at least some of the typical dysmorphic features and, all except child 5 , had the peripheral oedema associated with PEHO syndrome. Child 2 initially showed myoclonic jerks before infantile spasms developed, whereas in child 1 , the spasms were replaced by other seizure types including startle seizures and generalised tonic seizures. In the elder two children (children 1 and 2), EEG demonstrated classical hypsarrhythmia, whereas in the younger three (children 3, 4 and 5), the EEG was highly abnormal with an appearance consistent with infantile spasms. Children 1, 2, 3 and 5 displayed optic atrophy before 2 years, but child 4 did not have documented optic atrophy. In this child, visual fixation was reduced at 7 months, but ophthalmological review was not repeated after this. Child 1 had an MRI scan at 9 months of age which demonstrated a small pons, medulla, cerebral peduncles and cerebellar hemispheres. However, child 2 had a normal MRI at 6 months of age including a normal cerebellum and level of myelination. Child 3 died from pneumonia at 15 years and did not have any imaging. We were unable to obtain the images or 

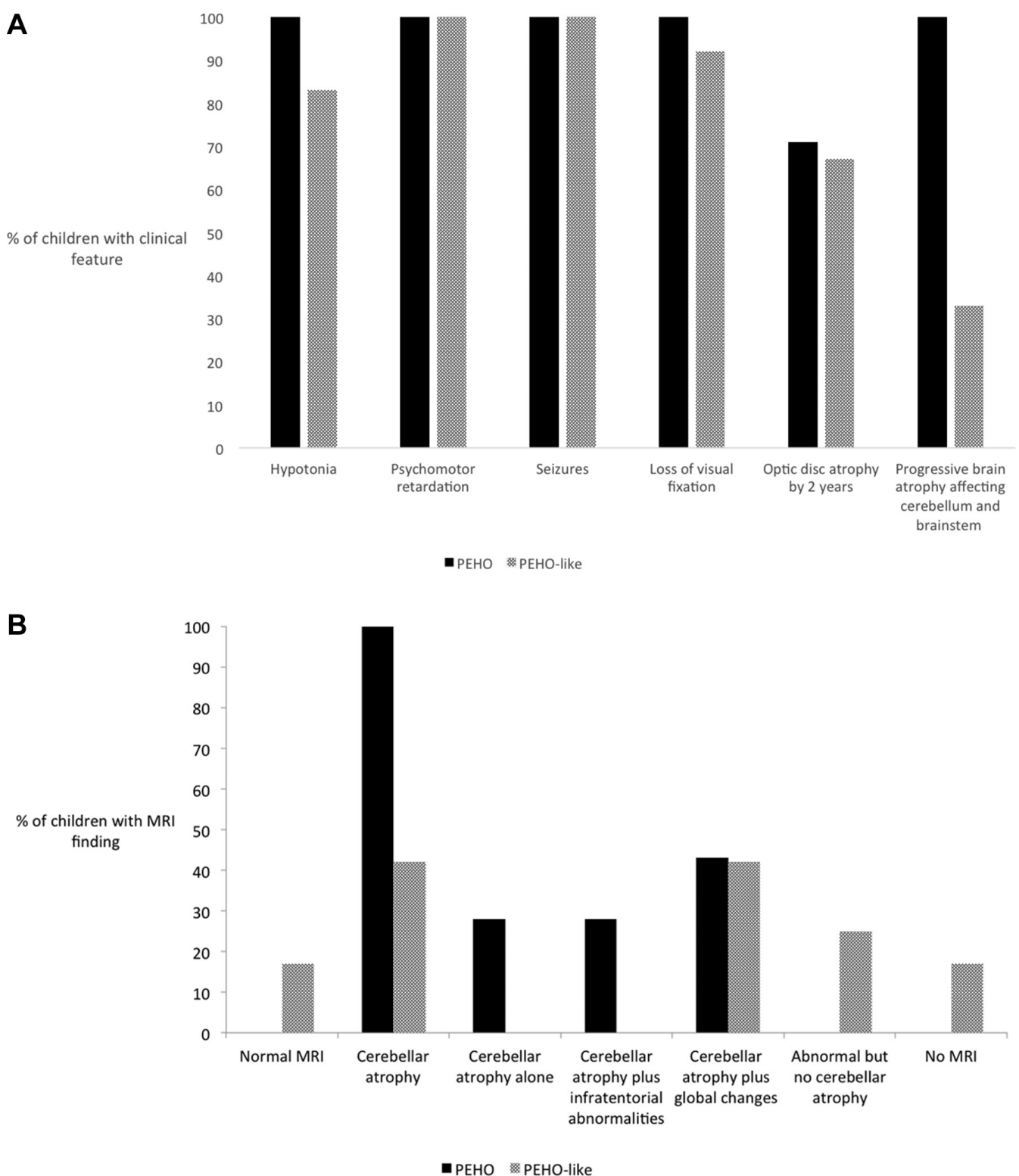

Figure 1 (A) Column graph illustrating the percentage of children, in both the PEHO and the PEHO-like cohort, displaying each of the features listed as essential for the diagnosis of PEHO (Somer 1993). Note that the feature of optic disc atrophy is not seen in all those diagnosed with PEHO because some died before it may be expected to have developed. (B) Column chart illustrating the variety seen in the MRI findings of the children in this cohort. PEHO, progressive encephalopathy, hypsarrhythmia and optic atrophy.

the report for the MRI of child 4. Child 5 had an MRI at only 14 days old which showed cerebellar atrophy.

In family B, there were three affected sisters (figure 3B and children 8-10 in table 2) born to non-consanguineous parents, two of whom have been described previously. ${ }^{11}$ Using Somer's criteria, all three children would be classified as having PEHOlike syndrome because cerebellar atrophy was lacking. The elder sisters (children 8 and 9) displayed supratentorial atrophy with delayed myelination. Child 8's scan was done at 7 months; child 9 had imaging at an unknown age. Child 10 had a normal MRI undertaken before her death at aged 21 months. All three had abnormalities of vision — child 8 lacked VEPs at 4 months of age, consistent with optic atrophy or cortical blindness; child 9 had pale optic discs by 1 month of age and child 10 was documented as having delayed visual maturation and died at aged 21 months. All three had microcephaly. Children 8 and 9 had the characteristic dysmorphic features of PEHO syndrome, whereas child
10 had different dysmorphic features. All three children were hypotonic and had hypsarrhythmia on EEG.

Family C included three affected children (children 14-16 in table 2) within two sibships in a consanguineous pedigree who all displayed a phenotype consistent with PEHO- like syndrome. A common genetic abnormality has been elucidated. ${ }^{31}$ The three children presented at birth with microcephaly, hypotonia with poor motor control and an onset of seizures within the first 2 weeks. The seizures were initially myoclonic jerks and infantile spasms in all three; children 15 and 16 later developed other seizure types. All three had absence or early loss of visual fixation with atrophy of the optic disc by 2 years and on neuroimaging progressive and predominantly infratentorial brain atrophy as well as pachygyria of the frontal and parietal regions. Child 14 and child 15 had dysmyelination, and child 16 was too young for this to be assessed. Child 14 and child 16 demonstrated brisk tendon reflexes, whereas child 16 was too young for this to be 


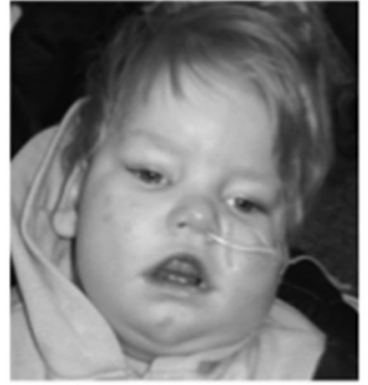

A.i

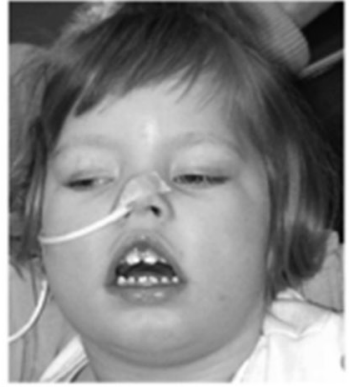

A.ii

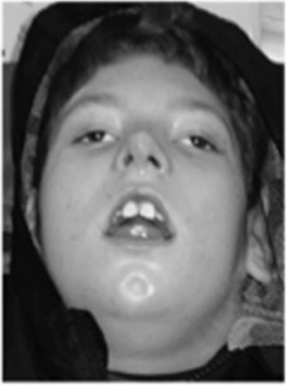

A.iii

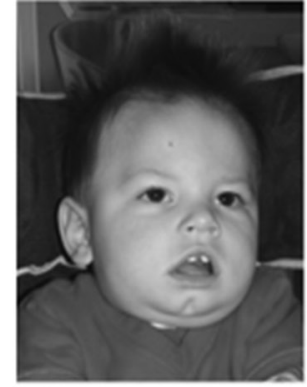

A.iv

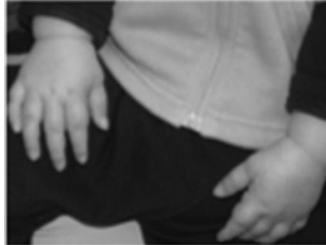

B.I

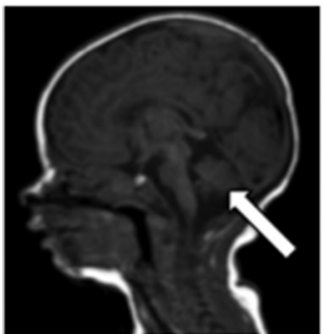

D.I

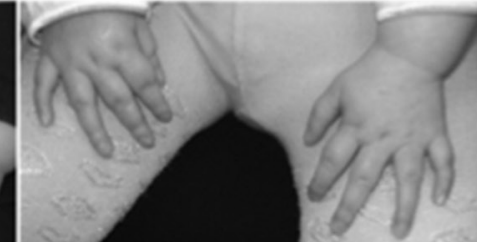

B.ii

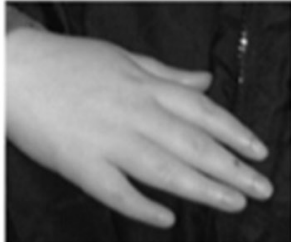

B.iii

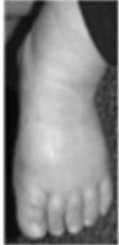

C.i

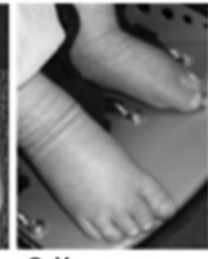

C.ii

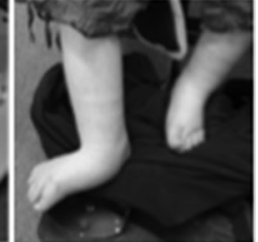

C.iii

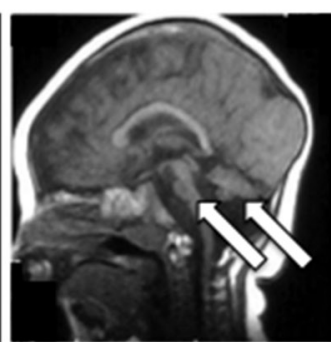

D.ii

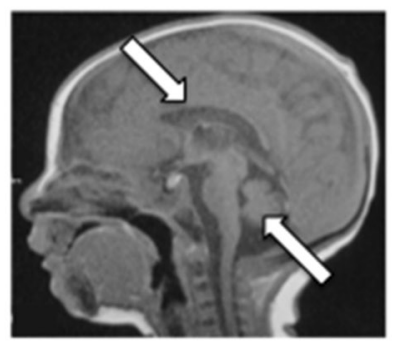

D.iii

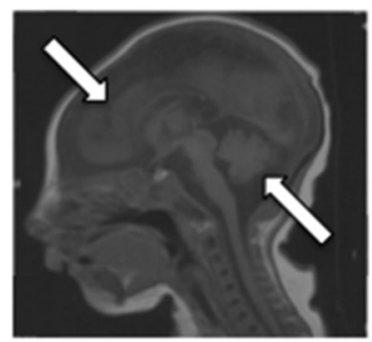

D.iv

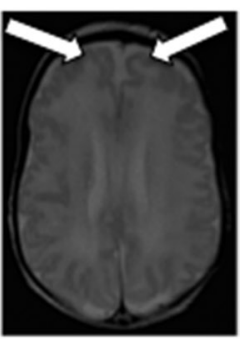

D.v

Figure 2 (A) Typical dysmorphic faces (narrow forehead, epicanthic folds, short nose, open mouth and receding chin) in children with PEHO (A.i-child 1 and A.iv — child 5) and PEHO-like syndromes (A.ii-child 2 and A.iii-child 3). Typical oedema of the hands (B) and feet (C) in children with PEHO (B.i, C.i and C.ii) and PEHO-like syndrome (B.ii, B.iii and C.iii). (D) Illustrative MRI findings: in children with PEHO: (D.i) sagittal T1 images showing hypoplasia of cerebellar vermis and volume loss of inferior cerebellar hemispheres, (D.ii) progressive cerebellar and brainstem atrophy, mild supratentorial atrophy, abnormal neuronal migration and abnormal myelination, (D.iii) cerebellar hypoplasia and thin corpus callosum, (D.v) axial T2 images showing frontal cortical polymicrogyria. In a child with PEHO-like syndrome, (D.iv) sagittal T1 images showing predominant cerebellar vermian hypoplasia, white matter volume loss with pachygyria and agyria. PEHO, progressive encephalopathy, hypsarrhythmia and optic atrophy.

assessed. All three had the dysmorphic features and oedema associated with PEHO syndrome.

\section{Genetic findings}

We discovered seven mutations (five $A C M G$ 'pathogenic' and two in SCN1A and SCN2A 'likely pathogenic's2) in 8 out of the 12 included families, all three families with multiple affected children, five of the nine singletons and in total 15 out of 19 children. All mutations were confirmed by Sanger sequencing. None are present in the Exome Aggregation Consortium (ExAC) or Exome Variant Server (EVS) variant databases, with the exception of the SNP rs114925667 in UBA5. All parents were unaffected. Families are annotated when parents are consanguineously related. No disease-causing copy number variants were identified through microarray analysis.

\section{Children 1 to 5 (family A)-PCLO}

Three of these children had PEHO-like syndrome, and two had PEHO syndrome. All five had biallelic nonsense variants in the gene PCLO (figure 3A); c.2703C>T p.Gln901*ter and c.7080C > G p.Tyr2360"ter. Each parent had one of the two variants. PCLO, which encodes the protein PICOLLO, was discovered in Drosophila as a gene essential for central nervous system synapse formation and function. We considered that these variants were pathogenic null alleles causative of the phenotype.

Homozygous nonsense PCLO variants (c.10624C > T and p.Arg3542*) have been reported previously in a family with pontocerebellar hypoplasia type $3 .^{33}$ The four affected individuals in this family presented with truncal hypotonia with increased deep tendon reflexes and had severe global developmental delay and seizures in the first year of life. Two had optic atrophy, and one had a brain MRI showing diffuse atrophy most marked in the cerebellum.

\section{Child 6-SCN2A}

One child with PEHO syndrome was found to have a heterozygous SCN2A mutation c.743T>C p.Leu248Pro. SCN2A is a voltage-gated sodium channel expressed widely on neurons. We considered this mutation as likely pathogenic as Leu248 is invariant in vertebrate SCN2A proteins, found at the equivalent position in $S C N 1 A / 3 A / 4 A / 5 A / 6 A / 8 A / 9 A / 10 A / 11 A$, and $S C N 2 A$ variants affecting closely located amino acids (p.Arg223Gln, p.Met252 Val and p.Ala263Val) are all reported to cause seizure disorders. We were unable to determine if the mutation was de novo, although it is not reported in EVS or ExAC. SCN2A heterozygous mutations are reported to cause EIEE type 11 (EIEE11-OMIM 613721) and benign familial infantile seizures 


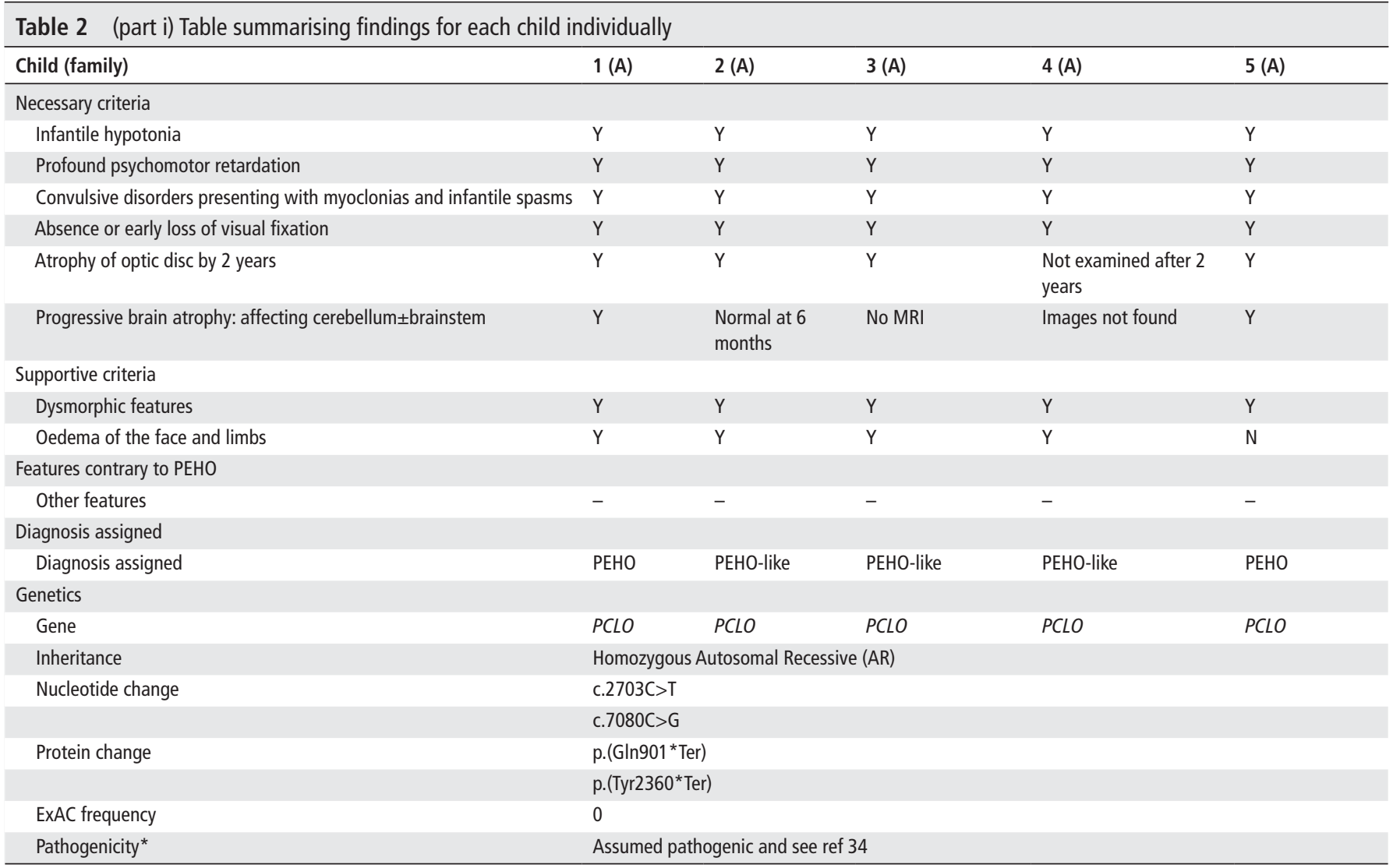

Children 1-5 are from family A; children 8-10 are from family B; children 14-16 are from family C.

${ }^{*}$ For each mutation pathogenicity, details are within the paper. Here we give either a reference confirming pathogenicity or where this is unavailable, the SIFT score ().

EXAc, Exome Aggregation Consortium; PEHO, progressive encephalopathy, hypsarrhythmia and optic atrophy; SIFT, Scale Invariant Feature Transform.

type 3 (OMIM 607745); however, PEHO phenotypic features have not been previously reported.

\section{Children 7 and 19-PLAA}

Two children from different families, both born to consanguineous first-cousin parents, both had the same homozygous pathogenic variant in the gene PLAA; c.68G > T p.Gly23Val. The families were not known to be related, but both families originate from the same region of Pakistan. One child had a PEHO phenotype, and the other had PEHO-like syndrome (due to early hypertonia). These children, a further family, and evidence of variant pathogenicity have been reported previously. ${ }^{26} P L A A$ encodes for the phospholipase A2-activating protein, is involved in the maintenance of ubiquitin levels and is strongly expressed in the central nervous system. However, the phenotypic human consequences of pathogenic variants have not been previously described.

\section{Children 8 to 10 (family B)-UBA5}

Three children had a PEHO-like diagnosis. Two were compound heterozygotes for the UBA5 variants (figure 3B): c. $1214 \mathrm{~A}>\mathrm{T}$ p. ter405Leu $+12 *$ ter and c. $1111 \mathrm{G}>\mathrm{A}$ p.Ala371Thr. DNA from the third sibling could not be sequenced. Each parent carried one of the two variants. We considered the variant p.ter405Leu+12*ter likely pathogenic given the evolutionarily conserved size and C-terminus of UBA5, and that UBA5 functions in a complex as a dimer with UFM1 and UFC1, which is bound with the C-terminal peptides of UBA5. ${ }^{35}$ The c. $1111 \mathrm{G}>\mathrm{Ap}$.Ala371Thr variant is the recorded SNP rs114925667 with a population frequency in EVS of $0.0015(20 / 12976)$ and in ExAC of 0.0018
(223/121150). It has been shown to be a pathogenic hypomorphic variant affecting UBA5 function. ${ }^{36}$ This pathogenic SNP was found as the second mutation in nine children reported with a severe infantile-onset encephalopathy, and in each of the five families described, the first variant was a nonsense or pathogenic splice site variant. The phenotype of these children would fit as PEHO-like syndrome: truncal hypotonia and later spasticity, most had infantile spasms and epileptic seizures and secondary microcephaly, some had peripheral oedema, brain MRI (when able to be performed) showed subtle findings including mild cerebral or cerebellar atrophy and all but one had severe developmental delay. A concurrent paper also described five further children with a PEHO-like phenotype (although only two had cerebellar atrophy) and biallelic missense variants in UBA5; in three cases, the second variant again was c.1111G $>$ Ap. Ala371Thr rs114925667. ${ }^{37}$

\section{Child 12-CASK}

This female had a de novo, heterozygous nonsense likely pathogenic variant in exon 3 of CASK; c.274C >A, p.(Glu92*Ter). Similar variants in this gene have been reported to cause a syndrome comprising severe intellectual disability, progressive microcephaly, axial hypotonia, pontine and cerebellar hypoplasia and optic atrophy-but only in females with heterozygous pathogenic variants. ${ }^{38}$ The peripheral oedema seen in our case had not been previously reported.

\section{Children 14 to 16 (family C)-CCDC88A}

Within a consanguineous family, two siblings and a cousin had a PEHO-like condition, which we have previously described. ${ }^{31}$ 
Table 2 (part ii) Table summarising findings for each child individually

\begin{tabular}{|c|c|c|c|c|c|c|}
\hline Child (family) & 6 & 7 & $8(B)$ & $9(\mathrm{~B})$ & 10 (B) & 11 \\
\hline \multicolumn{7}{|l|}{ Necessary criteria } \\
\hline Infantile hypotonia & $Y$ & $Y$ & $Y$ & $Y$ & $\mathrm{Y}$ & $\mathrm{Y}$ \\
\hline $\begin{array}{l}\text { Profound psychomotor } \\
\text { retardation }\end{array}$ & Y & $Y$ & $Y$ & $Y$ & $Y$ & $Y$ \\
\hline $\begin{array}{l}\text { Convulsive disorders } \\
\text { presenting with } \\
\text { myoclonias and infantile } \\
\text { spasms }\end{array}$ & Y & Y & Y & $Y$ & Y & $Y$ \\
\hline $\begin{array}{l}\text { Absence or early loss of } \\
\text { visual fixation }\end{array}$ & Y & $Y$ & Y & Y & Y & Y \\
\hline $\begin{array}{l}\text { Atrophy of optic disc by } \\
2 \text { years }\end{array}$ & Y & $<2$ years & Absent VEP & $Y$ & Died $<2$ years & Died $<2$ years \\
\hline $\begin{array}{l}\text { Progressive brain } \\
\text { atrophy: affecting } \\
\text { cerebellum } \pm \text { brainstem }\end{array}$ & Y & Y & $\begin{array}{l}\mathrm{N} \text { (supratentorial } \\
\text { atrophy; delayed } \\
\text { myelination) }\end{array}$ & & Normal & Y \\
\hline \multicolumn{7}{|l|}{ Supportive criteria } \\
\hline Dysmorphic features & Y & Y & Y & Y & Y & Y \\
\hline $\begin{array}{l}\text { Oedema of the face and } \\
\text { limbs }\end{array}$ & Y & $Y$ & $Y$ & $Y$ & $\mathrm{~N}$ & $Y$ \\
\hline \multicolumn{7}{|l|}{ Features contrary to PEHO } \\
\hline Other features & - & - & - & - & - & - \\
\hline \multicolumn{7}{|l|}{ Diagnosis assigned } \\
\hline Diagnosis assigned & PEHO & PEHO & PEHO-like & PEHO-like & PEHO-like & PEHO \\
\hline \multicolumn{7}{|l|}{ Genetics } \\
\hline Gene & $S C N 2 A$ & PLAA & UBA5 & UBA5 & $\begin{array}{l}\text { Unable to sequence } \\
\text { DNA }\end{array}$ & $\begin{array}{l}\text { No clear pathogenic } \\
\text { mutation found }\end{array}$ \\
\hline Inheritance & Heterozygous AD & Homozygous AD & De novo $A D$ & Heterozygous AD & & \\
\hline \multirow[t]{2}{*}{ Nucleotide change } & c. $743 \mathrm{~T}>\mathrm{C}$ & c. $68 \mathrm{G}>\mathrm{T}$ & c. $1214 \mathrm{~A}>\mathrm{T}$ & & & \\
\hline & & & c. $1111 \mathrm{G}>\mathrm{A}$ & & & \\
\hline \multirow[t]{2}{*}{ Protein change } & p.(Leu248Pro) & p.Gly23Val & p.(ter405Leu+12*Ter) & & & \\
\hline & & & p.(Ala371Thr) & & & \\
\hline ExAC frequency & 0 & 0 & 0 & & & \\
\hline Pathogenicity* & 0 & Ref 26 & $\begin{array}{l}\text { Assumed pathogenic } \\
\text { see refs } 36 \text { and } 37\end{array}$ & & & \\
\hline
\end{tabular}

Children 1-5 are from family $A$; children 8-10 are from family $B$; children $14-16$ are from family $C$.

${ }^{*}$ For each mutation pathogenicity, details are within the paper. Here we give either a reference confirming pathogenicity or where this is unavailable, the SIFT score ().

ExAc, Exome Aggregation Consortium; PEHO, progressive encephalopathy, hypsarrhythmia and optic atrophy; SIFT, Scale Invariant Feature Transform; VEP, visual evoked potentials.

The affected children had a homozygous, and the parents the heterozygous variant, c.2313delT, p.Leu772*ter in the gene CCDC88A. CCDC88A encodes for the protein coiled-coil domain containing $88 \mathrm{~A}$, which is more commonly known as GIRDIN. GIRDIN has multiple roles involving cell migration and determining cell polarity, particularly evident in neurons. ${ }^{3940}$ The human PEHO-like syndrome was reported to have significant overlap to the GIRDIN knockout mice. ${ }^{31}$

\section{Child 17-SCN1A}

A child with a PEHO-like phenotype was found to have a heterozygous SCN1A variant c.1252A $>$ C p.Iso418Leu. This apparently trivial change occurs in the intracellular portion of the domain I-S6 transmembrane domain. This is a critical region of the intracellular pore within the Nav1.7 protein, which is capable of being closed or open to allow $\mathrm{Na}^{+}$to enter the cell. The surrounding peptide sequence NLILAVVAMA is conserved in all human Nav1.n proteins (except Nav1.9-where it is NLTLAVVAMA, in all vertebrate Nav1.7 proteins, and in Drosophila paralytic). Parents were unavailable for testing.

\section{Children 11,13 and 18}

In three children with a PEHO-like phenotype, no clear pathogenic gene variants were found.

\section{Gene mutations previously reported to cause PEHO but not found in our cohort}

ZNHIT3: The cause of Finnish PEHO syndrome has recently been revealed to be homozygous pathogenic variants in ZNHIT3. $^{41}$

KIF1A: PEHO or PEHO-like syndrome has been reported in children with de novo mutations of the motor domain of KIF1A. ${ }^{21}$

\section{DISCUSSION}

We have found clinical and genetic heterogeneity in PEHO. The original Finnish cohort was ethnically homogeneous, unified by one common mutation in ZNHIT3. ${ }^{41}$ It differs from our ethnically diverse cohort-children of white British, Albanian, Sudanese and Pakistani heritage. We saw fewer pure PEHO cases. Discordance, that is, PEHO and PEHO-like syndrome, existed within the same pedigree. 
Table 2 (part iii) Table summarising findings for each child individually

\begin{tabular}{|c|c|c|c|c|c|}
\hline Child (family) & 12 & 13 & $14(C)$ & $15(C)$ & $16(C)$ \\
\hline \multicolumn{6}{|l|}{ Necessary criteria } \\
\hline Infantile hypotonia & Y & Y & Y & Y & Y \\
\hline Profound psychomotor retardation & Y & Y & Y & Y & Y \\
\hline $\begin{array}{l}\text { Convulsive disorders presenting with } \\
\text { myoclonias and infantile spasms }\end{array}$ & Y & Y & Y & Y & Y \\
\hline Absence or early loss of visual fixation & Y & $\mathrm{N}$ & Y & Y & Y \\
\hline Atrophy of optic disc by 2 years & Y & $\mathrm{N}$ & Y & Y & Y \\
\hline $\begin{array}{l}\text { Progressive brain atrophy: affecting } \\
\text { cerebellum } \pm \text { brainstem }\end{array}$ & Y & $\mathrm{N}$ & Y & Y & Y \\
\hline \multicolumn{6}{|l|}{ Supportive criteria } \\
\hline Dysmorphic features & Y & Y & Y & Y & Y \\
\hline Oedema of the face and limbs & Y & Y & Y & Y & Y \\
\hline \multicolumn{6}{|l|}{ Features contrary to PEHO } \\
\hline \multirow[t]{2}{*}{ Other features } & - & - & - & Microcephaly at birth & Microcephaly at birth \\
\hline & & & & $\begin{array}{l}\text { Abnormal gyral } \\
\text { formation }\end{array}$ & $\begin{array}{l}\text { Abnormal gyral } \\
\text { formation }\end{array}$ \\
\hline \multicolumn{6}{|l|}{ Diagnosis assigned } \\
\hline Diagnosis assigned & PEHO & PEHO-like & PEHO & PEHO-like & PEHO-like \\
\hline \multicolumn{6}{|l|}{ Genetics } \\
\hline Gene & CASK & $\begin{array}{l}\text { No pathogenic mutation } \\
\text { found }\end{array}$ & $C C D C 88 A$ & & \\
\hline Inheritance & De novo $A D$ & & Homozygous AD & & \\
\hline Nucleotide change & c. $274 C>A$ & & c.2313delT & & \\
\hline Protein change & p.(Glu92*Ter) & & p.(Leu772*Ter) & & \\
\hline ExAC frequency & 0 & 0 & 0 & & \\
\hline Pathogenicity* & See ref 38 & & See ref 31 & & \\
\hline
\end{tabular}

Children 1-5 are from family A; children 8-10 are from family B; children 14-16 are from family $C$.

*For each mutation pathogenicity, details are within the paper. Here we give either a reference confirming pathogenicity or where this is unavailable, the SIFT score ().

ExAc, Exome Aggregation Consortium; PEHO, progressive encephalopathy, hypsarrhythmia and optic atrophy; SIFT, Scale Invariant Feature Transform.

A number of entities influence whether the outcome would be PEHO or PEHO-like syndrome. Of the 'essential' features, all children in this cohort including those with PEHO-like syndrome had psychomotor delay and seizures; all except two had severe hypotonia, whereas two initially had reported hypertonia, but later were noted to have normal to low tone. Of the supporting characteristics, we observed that all had dysmorphic features and all except two had oedema of the face and limbs recorded. We found that the majority of children had a striking feature of extreme sleepiness in excess of that seen on most children with other epileptic encephalopathies. Some of the criteria for diagnosis are likely to be age-related; optic atrophy gradually develops and should be present by 2 years; also, the majority developed hypotonia by the end of the first year, but two developed it earlier.

There was clinical diversity within the ophthalmic findings-even within the same family. Eighteen of the children had ophthalmic abnormalities with visual inattention, which fulfils half of the essential criterion for ophthalmic signs. Only 13 had optic atrophy possibly due to early death prior to its development/assessment.

There was neuroradiological variability. We classified only those with evidence of infratentorial, especially cerebellar atrophy, as having PEHO. However, the range of abnormalities varied from pure volume loss of the cerebellum to changes affecting the brain globally. Some did not satisfy the PEHO essential criteria, but showed abnormal myelination, which would be supportive of PEHO. Three of the cohort had findings consistent with PEHO, but additionally had evidence of pachygyria which would argue against a PEHO diagnosis, placing them in the PEHO-like diagnostic category. A small number of children had normal MRI findings. There are reports of the progressive nature of MRI findings in PEHO. ${ }^{17} 18$ This supports the suggestion that the essential diagnostic criteria should be broader, including more generalised findings of brain atrophy or dysmyelination, and not remain restricted to the cerebellum. Serial MRIs through the condition would be more reliable, but not always clinically justifiable.

We report the clinical variation within affected families. Intrafamilial and interfamilial variability between families with the same genetic variant(s) leads one to question the validity of the distinction between PEHO and PEHO-like syndrome. From this cohort, it is clear that PEHO-like syndrome is not a distinct clinical entity in its own right. This intrafamilial variability also supports the argument that the MRI and ophthalmic findings, which are currently essential criteria for PEHO, should be altered. Some of the divergence in this cohort may be due to features occurring later and not being present at the time of assessment. We feel that the distinction between PEHO and PEHO-like is not clinically useful as they both represent the clinical endpoint of the different genetic epilepsies on the infantile-onset developmental and epileptic encephalopathy (DEE) spectrum.

In our cohort, we found marked genetic heterogeneity in the likely cause of PEHO/PEHO-like syndrome. We identified likely pathogenic variants in seven different genes. None of the patients in our cohort had variants in ZNHIT3 or KIF1A which are known to cause PEHO and PEHO-like syndrome. Our patients demonstrated different inheritance patterns of their PEHO/PEHO-like syndrome including autosomal recessive, dominant and $\mathrm{X}$ linked dominant. Reviewing the functions of our PEHO genes, there is no obvious shared function to suggest a common pathogenesis 
Table 2 (part iv) Table summarising findings for each child individually

\begin{tabular}{|c|c|c|c|c|}
\hline Child (family) & 17 & 18 & 19 & 20 \\
\hline \multicolumn{5}{|l|}{ Necessary criteria } \\
\hline Infantile hypotonia & Y & $\mathrm{N}$ & $\mathrm{N}$ & Y \\
\hline Profound psychomotor retardation & Y & Y & Y & Y \\
\hline $\begin{array}{l}\text { Convulsive disorders presenting with myoclonias and infantile } \\
\text { spasms }\end{array}$ & Y & Y & Y & Y \\
\hline Absence or early loss of visual fixation & Y & Y & Y & $?$ \\
\hline Atrophy of optic disc by 2 years & Y & Y & Y & $\mathrm{N}$ \\
\hline Progressive brain atrophy: affecting cerebellum \pm brainstem & Y & $?$ & Y & $\mathrm{N}$ \\
\hline \multicolumn{5}{|l|}{ Supportive criteria } \\
\hline Dysmorphic features & Y & Y & Y & $\mathrm{N}$ \\
\hline Oedema of the face and limbs & Y & Y & Y & Y \\
\hline \multicolumn{5}{|l|}{ Features contrary to PEHO } \\
\hline \multirow[t]{2}{*}{ Other features } & Microcephaly at birth & Hypertonia in infancy & Hypertonia in infancy & - \\
\hline & Abnormal gyral formation & & & \\
\hline \multicolumn{5}{|l|}{ Diagnosis assigned } \\
\hline Diagnosis assigned & PEHO-like & PEHO-like & PEHO-like & Excluded \\
\hline \multicolumn{5}{|l|}{ Genetics } \\
\hline Gene & SCN1A & $\begin{array}{l}\text { No clear pathogenic } \\
\text { mutation found }\end{array}$ & PLAA & \\
\hline Inheritance & Heterozygous AD & & Homozygous AD & \\
\hline Nucleotide change & c. $1252 A>C$ & & c. $68 \mathrm{G}>\mathrm{T}$ & \\
\hline Protein change & p.(Iso418Leu) & & p.(Gly23Val) & \\
\hline ExAC frequency & 0 & & 0 & \\
\hline Pathogenicity* & $\mathrm{SIFT}=0.01$ & & SIFT $=0.01$ and see ref 26 & \\
\hline
\end{tabular}

Children $1-5$ are from family $A$; children $8-10$ are from family $B$; children $14-16$ are from family $C$.

${ }^{*}$ For each mutation pathogenicity, details are within the paper. Here we give either a reference confirming pathogenicity or where this is unavailable, the SIFT score ().

EXAc, Exome Aggregation Consortium; PEHO, progressive encephalopathy, hypsarrhythmia and optic atrophy; SIFT, Scale Invariant Feature Transform.

A

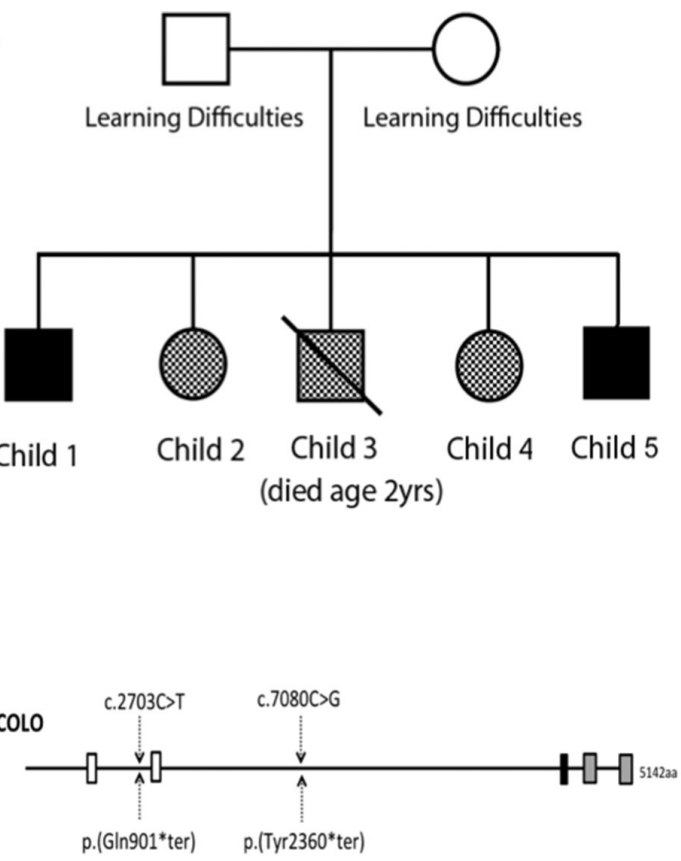

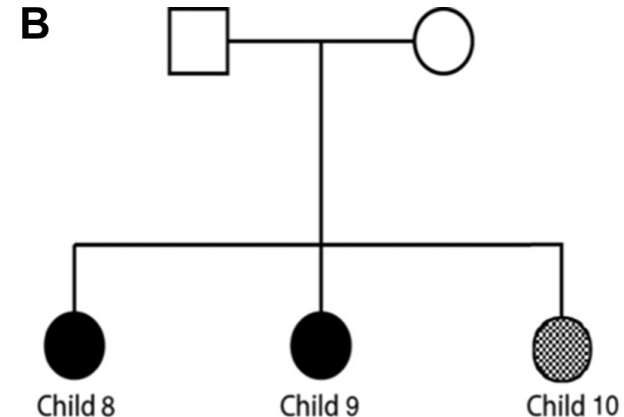

(died age 8yrs)

Figure 3 Family trees for families A and B (black fill—PEHO, black and white chequered—PEHO-like syndrome, white—unaffected). The number given to each affected child correlates with the child number used in table 2. Only parents and affected children are shown in the family tree. Unaffected siblings are not included. The PEHO-related variants identified in the PCLO and UBA5 genes and their proteins in these families are illustrated below (N.B., the genotype for child 10 is unknown). Mutations shown as nucleotide change above the linear protein cartoon and below for the protein change. Domains for $P C L O$ from left to right: in white, FYVE1 and FYVE2; in black PDZ and in grey RIM-C1 and RIM-C2. The ThiF domain of UBA5 is shown as a white box. See Nahorski et $a{ }^{31}$ for family tree for family $C$ and illustration of CCDC88A variants. Family tree for family $A$ and variants in the PCLO gene and its protein. Family tree for family $B$ and variants in the UBA5 gene and its protein. PEHO, progressive encephalopathy, hypsarrhythmia and optic atrophy. 
for PEHO syndrome; for example, PCLO and PLAA are components of synapses, $S C N 1 A$ and $S C N 2 A$ are essential for neuronal membrane potential and UBA5 is involved in ufmylation.

\section{CONCLUSIONS}

We conclude that PEHO and PEHO-like syndrome are clinically and genetically diverse entities and represent the endpoint of many severe epileptic disorders. The aetiological diagnosis of early-onset severe epileptic encephalopathies remains extremely challenging given the clinical and genetic heterogeneity. Our study is a reminder of the complexity of investigating children with DEE. These children need careful clinical evaluation and investigation with a genetic DEE panel which includes genes reported in association with a PEHO/PEHO-like phenotype. This study suggests that 'PEHO' is no longer an appropriate clinical label outside of the Finnish population.

Note:

Since submission of this paper, the causative gene change in child 11 has been shown to be a homozygous missense mutation in UFM1 c.241C>T, p.(Arg81Cys). Biochemical analysis and further case ascertainment was necessary before we could be sure of this. ${ }^{42}$

Acknowledgements We are grateful to Dr Daniela Pilz for expert discussions and Dr Justin Cross for his assistance with the interpretation of brain scans.

Contributors MC, BD-D, HH, ELW, AFB, SMZ, MS, APJP and CGW ascertained and clinically characterised cases. MC, APJP and CGW contributed to the planning, conducting and reporting of the work described in the article and will be the overall guarantors. MSN, KS and CGW carried out the molecular genetic work. BD-D and $\mathrm{HH}$ contributed to the writing of the manuscript. ELW, AFB, SMZ and MS helped in revising and editing the manuscript.

Funding MSN received funding from Wellcome Trust. CGW was supported in this research by Cambridge NIHR Biomedical Research Centre.

Competing interests None declared.

Patient consent Obtained.

Ethics approval Cambridge Research Ethics Committee.

Provenance and peer review Not commissioned; externally peer reviewed.

\section{REFERENCES}

1 Salonen R, Somer M, Haltia M, Lorentz M, Norio R. Progressive encephalopathy with edema, hypsarrhythmia, and optic atrophy (PEHO syndrome). Clin Genet 1991:39:287-93.

2 Haltia M, Somer M. Infantile cerebello-optic atrophy. Neuropathology of the progressive encephalopathy syndrome with edema, hypsarrhythmia and optic atrophy (the PEHO syndrome). Acta Neuropathol 1993;85:241-7.

3 Somer M. Diagnostic criteria and genetics of the PEHO syndrome. J Med Genet 1993:30:932-6

4 Somer M, Salonen O, Pihko H, et al. PEHO syndrome (progressive encephalopathy with edema, hypsarrhythmia, and optic atrophy): neuroradiologic findings. AJNR Am J Neuroradiol 1993;14:861-7.

5 Somer M, Sainio K. Epilepsy and the electroencephalogram in progressive encephalopathy with edema, hypsarrhythmia, and optic atrophy (the PEHO syndrome). Epilepsia 1993:34:727-31.

6 Chitty LS, Robb S, Berry C, Silver D, Baraitser M. PEHO or PEHO-like syndrome? Clin Dysmorphol 1996;5:143-52.

7 Field MJ, Grattan-Smith P, Piper SM, Thompson EM, Haan EA, Edwards M, James S, Wilkinson I, Adès LC. PEHO and PEHO-like syndromes: report of five Australian cases. Am J Med Genet A 2003;122A:6-12.

8 Salpietro V, Gitto E, Romeo A, Manti S, Granata F, Cilona S, De Vivo D, Valenti S, Fede C, Polizzi A, Briuglia S, Mankad K, Ruggieri M. Progressive encephalopathy with oedema, hypsarrhythmia and optic atrophy (PEHO syndrome): report of the first Italian cases. Child A J Pediatr 2013;1:1-2.

9 Fujimoto S, Yokochi K, Nakano M, Wada Y. Progressive encephalopathy with edema, hypsarrhythmia, and optic atrophy (PEHO syndrome) in two Japanese siblings. Neuropediatrics 1995;26:270-2.

10 Vanhatalo S, Somer M, Barth PG. Dutch patients with progressive encephalopathy with edema, hypsarrhythmia, and optic atrophy (PEHO) syndrome. Neuropediatrics 2002:33:100-4
11 Longman C, Tolmie J, McWilliam R, MacLennan A. Cranial magnetic resonance imaging mistakenly suggests prenatal ischaemia in PEHO-like syndrome. Clin Dysmorphol 2003;12:133-6.

12 Nieto-Barrera M, Nieto-Jiménez M, Díaz-Fernandez F, Campaña-Marchal C, Candau Fernández-Mensaque R. [Progressive encephalopathy with oedema, hypsarrhythmia and optic atrophy (PEHO syndrome). A case report]. Rev Neurol 2003;36:1044-6.

13 Klein A, Schmitt B, Boltshauser E. Progressive encephalopathy with edema, hypsarrhythmia and optic atrophy (PEHO) syndrome in a Swiss child. Eur J Paediatr Neurol 2004;8:317-21.

14 D'Arrigo S, Grazia BM, Faravelli F, Riva D, Pantaleoni C. Progressive encephalopathy with edema, hypsarrhythmia, and optic nerve atrophy (PEHO)-like syndrome: what diagnostic characteristics are defining? J Child Neurol 2005;20:454-6.

15 Alfadhel M, Yong SL, Lillquist Y, Langlois S. Precocious puberty in two girls with PEHO syndrome: a clinical feature not previously described. J Child Neurol 2011;26:851-7.

16 Caraballo RH, Carignani M, Chamoles N, Fejerman N. PEHO syndrome in 3 nonfinnish patients. Pediatr Neurol 1994;11:170.

17 Huisman TA, Klein A, Werner B, Straube T, Boltshauser E. Serial MR imaging, diffusion tensor imaging, and MR spectroscopic findings in a child with progressive encephalopathy, edema, hypsarrhythmia, and optic atrophy (PEHO) syndrome. AJNR Am J Neuroradiol 2006;27:1555-8.

18 Sonmez G, Aydinöz S, Mutlu H, Ozturk E, Onur Sildiroglu H, Süleymanoglu S, Tunca Keskin A. Serial MRI in a child with PEHO syndrome. J Neuroradiol 2007;34:281-3.

19 Riikonen R, Somer M, Turpeinen U. Low insulin-like growth factor (IGF-1) in the cerebrospinal fluid of children with progressive encephalopathy, hypsarrhythmia, and optic atrophy (PEHO) syndrome and cerebellar degeneration. Epilepsia 1999:40:1642-8.

20 Vanhatalo S, Riikonen R. Markedly elevated nitrate/nitrite levels in the cerebrospinal fluid of children with progressive encephalopathy with edema, hypsarrhythmia, and optic atrophy (PEHO syndrome). Epilepsia 2000;41:705-8.

21 Langlois S, Tarailo-Graovac M, Sayson B, Drögemöller B, Swenerton A, Ross CJ, Wasserman WW, van Karnebeek CD. De novo dominant variants affecting the motor domain of KIF1A are a cause of PEHO syndrome. Eur J Hum Genet 2016;24:949-53.

22 Gawlinski P, Posmyk R, Gambin T, Sielicka D, Chorazy M, Nowakowska B, Jhangiani SN, Muzny DM, Bekiesinska-Figatowska M, Bal J, Boerwinkle E, Gibbs RA, Lupski JR, Wiszniewski W. PEHO Syndrome May Represent Phenotypic Expansion at the Severe End of the Early-Onset Encephalopathies. Pediatr Neurol 2016;60:83-7.

23 Nahorski MS, Al-Gazali L, Hertecant J, Owen DJ, Borner GH, Chen YC, Benn CL, Carvalho OP, Shaikh SS, Phelan A, Robinson MS, Royle SJ, Woods CG. A novel disorder reveals clathrin heavy chain-22 is essential for human pain and touch development. Brain 2015;138:2147-60.

24 Stouffer K, Nahorski M, Moreno P, Sarveswaran N, Menon D, Lee M, Geoffrey Woods C. Functional SNP allele discovery (fSNPd): an approach to find highly penetrant, environmental-triggered genotypes underlying complex human phenotypes. $B M C$ Genomics 2017:18:1-7.

25 Chavali PL, Stojic L, Meredith LW, Joseph N, Nahorski MS, Sanford TJ, Sweeney TR, Krishna BA, Hosmillo M, Firth AE, Bayliss R, Marcelis CL, Lindsay S, Goodfellow I, Woods CG, Gergely F. Neurodevelopmental protein Musashi-1 interacts with the Zika genome and promotes viral replication. Science 2017:357:83-8.

26 Hall EA, Nahorski MS, Murray LM, Shaheen R, Perkins E, Dissanayake KN, Kristaryanto Y, Jones RA, Vogt J, Rivagorda M, Handley MT, Mali GR, Quidwai T, Soares DC, Keighren MA, McKie L, Mort RL, Gammoh N, Garcia-Munoz A, Davey T, Vermeren M, Walsh D, Budd P, Aligianis IA, Fageih E, Quigley AJ, Jackson IJ, Kulathu Y, Jackson M, Ribchester RR, von Kriegsheim A, Alkuraya FS, Woods CG, Maher ER, Mill P. PLAA mutations cause a lethal infantile epileptic encephalopathy by disrupting ubiquitin-mediated endolysosomal degradation of synaptic proteins. Am I Hum Genet 2017;100:706-24.

27 Rankin J, Brown R, Dobyns WB, Harington J, Patel J, Quinn M, Brown G. Pontocerebellar hypoplasia type 6: a British case with PEHO-like features. Am J Med Genet A 2010;152A:2079-84.

28 Karaca E, Harel T, Pehlivan D, Jhangiani SN, Gambin T, Coban Akdemir Z, GonzagaJauregui C, Erdin S, Bayram Y, Campbell IM, Hunter JV, Atik MM, Van Esch H, Yuan B, Wiszniewski W, Isikay S, Yesil G, Yuregir 00, Tug Bozdogan S, Aslan H, Aydin H, Tos T, Aksoy A, De Vivo DC, Jain P, Geckinli BB, Sezer O, Gul D, Durmaz B, Cogulu O, Ozkinay F, Topcu V, Candan S, Cebi AH, Ikbal M, Yilmaz Gulec E, Gezdirici A, Koparir E, Ekici F, Coskun S, Cicek S, Karaer K, Koparir A, Duz MB, Kirat E, Fenercioglu E, Ulucan H, Seven M, Guran T, Elcioglu N, Yildirim MS, Aktas D, Alikaşifoğlu M, Ture M, Yakut T, Overton JD, Yuksel A, Ozen M, Muzny DM, Adams DR, Boerwinkle E, Chung WK, Gibbs RA, Lupski JR. Genes that affect brain structure and function identified by rare variant analyses of mendelian neurologic disease. Neuron 2015;88:499-513.

29 Salpietro V, Zollo M, Vandrovcova J, Ryten M, Botia JA, Ferrucci V, Manole A, Efthymiou S, Al Mutairi F, Bertini E, Tartaglia M, Houlden H. The phenotypic and molecular spectrum of PEHO syndrome and PEHO-like disorders. Brain 2017;140:e49-2.

30 Zollo M, Ahmed M, Ferrucci V, Salpietro V, Asadzadeh F, Carotenuto M, Maroofian R, Al-Amri A, Singh R, Scognamiglio I, Mojarrad M, Musella L, Duilio A, Di Somma A, Karaca E, Rajab A, Al-Khayat A, Mohan Mohapatra T, Eslahi A, Ashrafzadeh F, Rawlins LE, Prasad R, Gupta R, Kumari P, Srivastava M, Cozzolino F, Kumar Rai S, Monti M, Harlalka GV, Simpson MA, Rich P, Al-Salmi F, Patton MA, Chioza BA, Efthymiou S, Granata F, Di Rosa G, Wiethoff S, Borgione E, Scuderi C, Mankad K, Hanna MG, Pucci 
P, Houlden H, Lupski JR, Crosby AH, Baple EL. PRUNE is crucial for normal brain development and mutated in microcephaly with neurodevelopmental impairment. Brain 2017;140:940-52.

31 Nahorski MS, Asai M, Wakeling E, Parker A, Asai N, Canham N, Holder SE, Chen YC, Dyer J, Brady AF, Takahashi M, Woods CG. CCDC88A mutations cause PEHO-like syndrome in humans and mouse. Brain 2016;139:1036-44.

32 Richards S, Aziz N, Bale S, Bick D, Das S, Gastier-Foster J, Grody WW, Hegde M, Lyon E, Spector E, Voelkerding K, Rehm HL. ACMG Laboratory Quality Assurance Committee. Standards and guidelines for the interpretation of sequence variants: a joint consensus recommendation of the American College of Medical Genetics and Genomics and the Association for Molecular Pathology. Genet Med 2015;17:405-23.

33 Rajab A, Mochida GH, Hill A, Ganesh V, Bodell A, Riaz A, Grant PE, Shugart YY, Walsh CA. A novel form of pontocerebellar hypoplasia maps to chromosome 7q11-21. Neurology 2003;60:1664-7.

34 Ahmed MY, Chioza BA, Rajab A, Schmitz-Abe K, Al-Khayat A, Al-Turki S, Baple EL, Patton MA, Al-Memar AY, Hurles ME, Partlow JN, Hill RS, Evrony GD, Servattalab S, Markianos K, Walsh CA, Crosby AH, Mochida GH. Loss of PCLO function underlies pontocerebellar hypoplasia type III. Neurology 2015;84:1745-50.

35 Oweis W, Padala P, Hassouna F, Cohen-Kfir E, Gibbs DR, Todd EA, Berndsen CE, Wiener R. Trans-Binding Mechanism of Ubiquitin-like Protein Activation Revealed by a UBA5-UFM1 Complex. Cell Rep 2016;16:3113-20.

36 Muona M, Ishimura R, Laari A, Ichimura Y, Linnankivi T, Keski-Filppula R, Herva R, Rantala H, Paetau A, Pöyhönen M, Obata M, Uemura T, Karhu T, Bizen N, Takebayashi H, McKee S, Parker MJ, Akawi N, McRae J, Hurles ME, Kuismin O, Kurki MI, Anttonen AK, Tanaka K, Palotie A, Waguri S, Lehesjoki AE, Komatsu M. DDD Study. Biallelic variants in UBA5 link dysfunctional UFM1 ubiquitin-like modifier pathway to severe infantile-onset encephalopathy. Am J Hum Genet 2016;99:683-94.

37 Colin E, Daniel J, Ziegler A, Wakim J, Scrivo A, Haack TB, Khiati S, Denommé AS, Amati-Bonneau P, Charif M, Procaccio V, Reynier P, Aleck KA, Botto LD, Herper CL, Kaiser CS, Nabbout R, N'Guyen S, Mora-Lorca JA, Assmann B, Christ S,
Meitinger T, Strom TM, Prokisch H, Miranda-Vizuete A, Hoffmann GF, Lenaers G, Bomont P, Liebau E, Bonneau D. FREX Consortium. Biallelic Variants in UBA5 Reveal that Disruption of the UFM1 Cascade Can Result in Early-Onset Encephalopathy. Am J Hum Genet 2016;99:695-703.

38 Moog U, Kutsche K, Kortüm F, Chilian B, Bierhals T, Apeshiotis N, Balg S, Chassaing N, Coubes C, Das S, Engels H, Van Esch H, Grasshoff U, Heise M, Isidor B, Jarvis J, Koehler U, Martin T, Oehl-Jaschkowitz B, Ortibus E, Pilz DT, Prabhakar P, Rappold G, Rau I, Rettenberger G, Schlüter G, Scott RH, Shoukier M, Wohlleber E, Zirn B, Dobyns WB, Uyanik G. Phenotypic spectrum associated with CASK loss-of-function mutations. J Med Genet 2011;48:741-51.

39 Ohara K, Enomoto A, Kato T, Hashimoto T, Isotani-Sakakibara M, Asai N, IshidaTakagishi M, Weng L, Nakayama M, Watanabe T, Kato K, Kaibuchi K, Murakumo Y, Hirooka Y, Goto H, Takahashi M. Involvement of Girdin in the determination of cell polarity during cell migration. PLoS One 2012;7:e36681-13.

40 Asai M, Asai N, Murata A, Yokota H, Ohmori K, Mii S, Enomoto A, Murakumo Y, Takahashi M. Similar phenotypes of Girdin germ-line and conditional knockout mice indicate a crucial role for Girdin in the nestin lineage. Biochem Biophys Res Commun 2012;426:533-8.

41 Anttonen AK, Laari A, Kousi M, Yang YJ, Jääskeläinen T, Somer M, Siintola E, Jakkula E, Muona M, Tegelberg S, Lönnqvist T, Pihko H, Valanne L, Paetau A, Lun MP, Hästbacka J, Kopra O, Joensuu T, Katsanis N, Lehtinen MK, Palvimo JJ, Lehesjoki AE. ZNHIT3 is defective in PEHO syndrome, a severe encephalopathy with cerebellar granule neuron loss. Brain 2017;140:1267-79.

42 Nahorski MS, Maddirevula S, Ishimura R, Alsahli S, Brady AF, Begemann A, Mizushima T, Guzmán-Vega FJ, Obata M, Ichimura Y, Alsaif HS, Anazi S, Ibrahim N, Abdulwahab F, Hashem M, Monies D, Abouelhoda M, Meyer BF, Alfadhel M, Eyaid W, Zweier M, Steindl K, Rauch A, Arold ST, Woods CG, Komatsu M, Alkuraya FS. Biallelic UFM1 and UFC1 mutations expand the essential role of ufmylation in brain development. Brain 2018;141:1934-45. 